\title{
Emission Character Study on temperature Combustion Performance of Electronic Controlled Diesel Engine Mixed with Butanol
}

\author{
Deng $H u^{1}$, Zhaoxia Huang ${ }^{3 *}$, Jialiang Huang ${ }^{1,2}$, Tao Deng ${ }^{1}$, Zi Xiao Ye ${ }^{1}$, and Jinyu Fan ${ }^{1,2}$ \\ ${ }^{1}$ Marine Engineering Institute, Jimei University, Xiamen 361021, China \\ ${ }^{2}$ Fujian Provincial Key Laboratory of Naval Architecture and Ocean Engineering, Xiamen 361021, China \\ ${ }^{3 *}$ School of Science, Jimei University, Xiamen 361021, China
}

\begin{abstract}
In this paper, through the electromechanical control modification of 4190 ZLC-2 diesel, the electronic fuel injection model is established by AMESim simulation software, and the high pressure circulation model of butanol/diesel dual fuel engine is established by AVL-FIRE software, the appropriate initial parameters module and corresponding boundary conditions are set. At the condition of low-temperature combustion through exhaust gas recirculation (EGR), in the optimization scheme studying the influence of butan blending ratio and EGR rate on diesel engine emissions. The result shows that the addition of butanol can improve the low temperature combustion, reducing the formation of $\mathrm{CO}$ and soot. The introduction of EGR can achieve low temperature combustion and significantly reduce NO emissions. The optimal parameter set for parameter matching is obtained: B20/EGR12.5\%.
\end{abstract}

\section{INTRODUCTION}

At present, the dependence on the international ship freight industry is becoming more and more important. Ship transportation accounts for more than $2 / 3$ of the total volume of international trade, Accounting for more than $90 \%$ of China's total import and export volume. In recent years, more stringent emission regulations[1] have formulated by the International Maritime Organization to Promote the development of diesel engine towards more energy saving direction ${ }^{[2]}$. As the second generation of new biofuels, butanol is easier to achieve clean combustion than traditional petroleum, and can well meet the storage and transportation of fuels in current energy transportation systems, and can be well mixed with diesel in the application process. Comparing to ethanol, butanol is closer to diesel in nature which has good application value $^{[3-5]}$. The research on butanol/diesel dual fuel engines by domestic and foreign research institutes mainly focuses on changing diesel engine operating parameter to analyze parameter changes on the influence of emissions ${ }^{[6-8]}$.In this paper, the AMEsim simulation software is used to establish an electronically controlled fuel injection model. The optimal combination of diesel engine operating parameters is obtained by adjusting input. The AMEsim and AVL-FIRE software are used to change the butanol blending ratio and EGR rate under constant operating parameters. Based on the result, the injection advance angle was changed and its influence on soot, nitrogen oxides and $\mathrm{CO}$ emissions were analyzed.

\section{MODEL ESTABLISHMENT AND VERIFICATION}

\subsection{Research Object and Model Establishment}

The research object of this paper is the 4190 marine medium-speed diesel engine ${ }^{[9]}$ After electronic control transformation, transforming the traditional mechanical fuel injection diesel engine into a time-controlled electronically controlled combination diesel engine ${ }^{[10]}$, as shown in Figure 1. The main parameters in the model are obtained through experimental measurements in combination with the operating parameters and structural parameters of the original machine. The cycle injection amount is set to $630 \mathrm{~mm} 3$, and the injection pressure is no less than $10 \mathrm{MPa}$. The aim of Orthogonal decomposition of the measured parameters is to obtain the optimal parameters combination : cam line speed $0.46 \mathrm{~mm} /{ }^{\circ} \mathrm{CA}$, injector nozzle number $\times$ nozzle diameter $10 \times 0.22 \mathrm{~mm}$, plunger diameter $15 \mathrm{~mm}$, high pressure tubing length $800 \mathrm{~mm}$, The high pressure oil pipe has a diameter of 1.5 $\mathrm{mm}$.

According to the actual structural parameters of the 4190 diesel engine, CAD is used to draw the one-half model of the combustion chamber center section and the combustion chamber $1 / 8$ calculation model. As shown in Figure 2, it is imported into the ESE module of AVL_FIRE[11-13], and the ESE module is automatically generation. The 3D moving mesh is shown in Figure 3, the

\footnotetext{
* Corresponding author: zxhuang@jimu.edu.cn
} 
mesh is divided and checked, and the solver parameters are set. The setting of the boundary condition parameters mainly depend on the temperature of each component of the model at the initial running time of the diesel engine. The one-dimensional model of the whole machine is constructed by AVL-BOOST and the boundary data is obtained through calculation. Boundary conditions: wall temperature $403.15 \mathrm{~K}$, piston temperature set to $631.25 \mathrm{~K}$, cylinder head temperature set to $542.25 \mathrm{~K}$. In the initial condition setting, the gas pressure and temperature at the intake valve closing time are obtained by the original machine date. The kinetic energy calculation formula is shown in formula (1)-(3) The initial conditions: TKE is 18.375 , the turbulent length scale (TLS) is $0.00624 \mathrm{~m}$ (diesel specification) ); one-eighth of the fuel injection is set to: $0.39479 \mathrm{~g} 8=0.04935 \mathrm{~g}$. The calculation formula is as shown in formula (4).

$$
\begin{aligned}
& T K E=(3 / 2) * \mathrm{u}^{2} \\
& \mathrm{u}=0.5 * \mathrm{C}_{\mathrm{m}} \\
& \mathrm{C}_{\mathrm{m}}=2 * \mathrm{~h} *(\mathrm{n} / 60)
\end{aligned}
$$

Where: $\mathrm{n}=$ Diesel engine speed $(\mathrm{r} / \mathrm{min})$

$\mathrm{Cm}=$ Average speed of the piston $(\mathrm{r} / \mathrm{min})$

$\mathrm{H}=\operatorname{stroke}(\mathrm{m})$

$\mathrm{U}=$ Turbulent pulsation velocity $(\mathrm{m} / \mathrm{s})$

$$
\mathrm{m}=\frac{b_{\varepsilon} p_{\varepsilon}}{120 n i} \tau
$$

where: $p_{\varepsilon}=$ Calibration power point fuel consumption rate[g/(Kw.h)]

$\mathrm{P}_{\varepsilon}$ - Calibration power( $\left.\mathrm{kW}\right)$

$\mathrm{\tau}=$ Calibration $\operatorname{speed}(\mathrm{r} / \mathrm{min})$

$\mathrm{n}=$ Calibration speed $(\mathrm{r} / \mathrm{min})$

$\mathrm{i}=$ Number of diesel cylinders

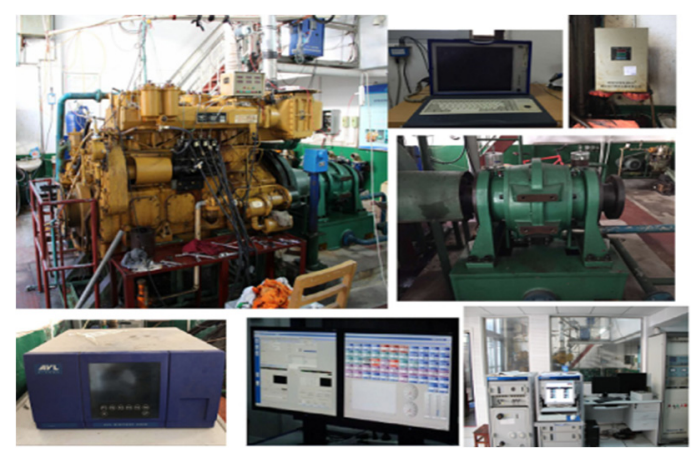

Fig.1 Electronically modified diesel engine

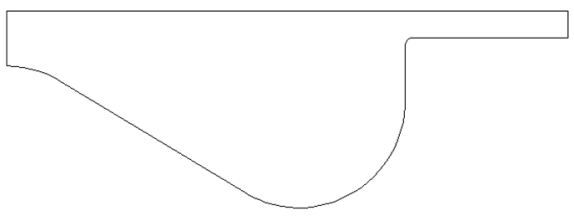

Figure 2 is a schematic diagram of the center section of the combustion chamber

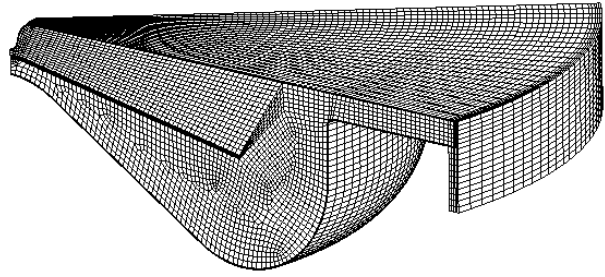

Figure.3One-eighth calculation model of the combustion chamber diesel engine

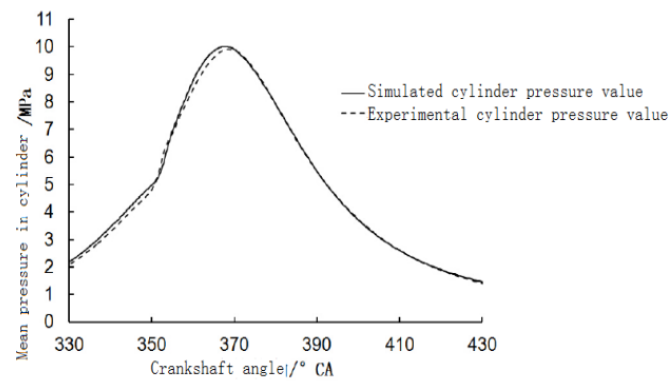

Figure.4Comparison of the simulated values of the cylinder pressure curve and the experimental values

\subsection{Model Verification}

In this paper, the mass fraction of butanol $(\mathrm{C} 4 \mathrm{H} 10 \mathrm{O})$ in the AVL_FIRE solver gas composition is set to 0 .Under the rated working condition, the cylinder pressure curve under the condition of pure diesel combustion in the model is compared to the measured cylinder pressure curve of the original machine test data. During contrast, The relevant parameters were adjusted continuously until the error of the two curves are within 5\%. As shown in Fig 4 , the above two curves have basically the same trend.The error is within 5\%, and the accuracy is high. Model can be used for simulation calculation research.

\section{EFFECT OF BUTANOL BLENDING RATIO AND EGR RATE ON DIESEL ENGINE EMMISION}

\subsection{Effect of Butanol Blending Ratio and EGR Rate on NO Emission}

Figure 5 is a graph of NO mass fraction at different EGR rates and butanol blending ratios. From the image change trend in the figure we can see that, at low EGR rate, 
the mass fraction of $\mathrm{NO}$ increases with the increase of butanol blending ratio decrease gradually with the increase of EGR rate, but at high EGR, the NO mass fraction of different blending ratios is opposite to that of low EGR. As the butanol blending ratio increases, the NO formation moment is extended backward.

The effect of butanol blending ratio on NO emission is that the cylinder temperature is higher at low EGR rate, and the butanol phase contains more oxygen than diesel. The larger the butanol blending ratio, the more the oxygen elements are contained. The environment of oxygen-rich is suitable for the formation of NO at high EGR rate, the cylinder temperature is reduced, the higher the calorific value of the fuel with lower butanol blending, the higher the in-cylinder temperature which is higher than that of other high butanol, the amount of formation of NO is relatively higher. the latent heat of vaporization of butanol is higher than diesel, and the amount of heat that needs to be absorbed is higher when the point of ignition is reached, which cause the retardation period is prolonged and the NO generation time is extended later ${ }^{[14]}$.

The effect of EGR change rate on NO emission is that can be seen from the figure that with the increase of EGR rate, the emission of NO decreases significantly, and the average temperature in the cylinder drops from the peak of $1800 \mathrm{~K}$ when EGR is $0 \%$ to the bottom of below $1600 \mathrm{~K}$ when the EGR is $12.5 \%$. Low temperature combustion has been basically achieved. The main reason above is that the inert gas that does not participate in the chemical reaction is increased, the specific heat capacity increases, the oxygen is diluted, and the retardation period is prolonged, therefore the mixed fuel is injected in the low temperature and oxygen-deficient environment. The NO emission is less affected by the proportion of butanol blended.
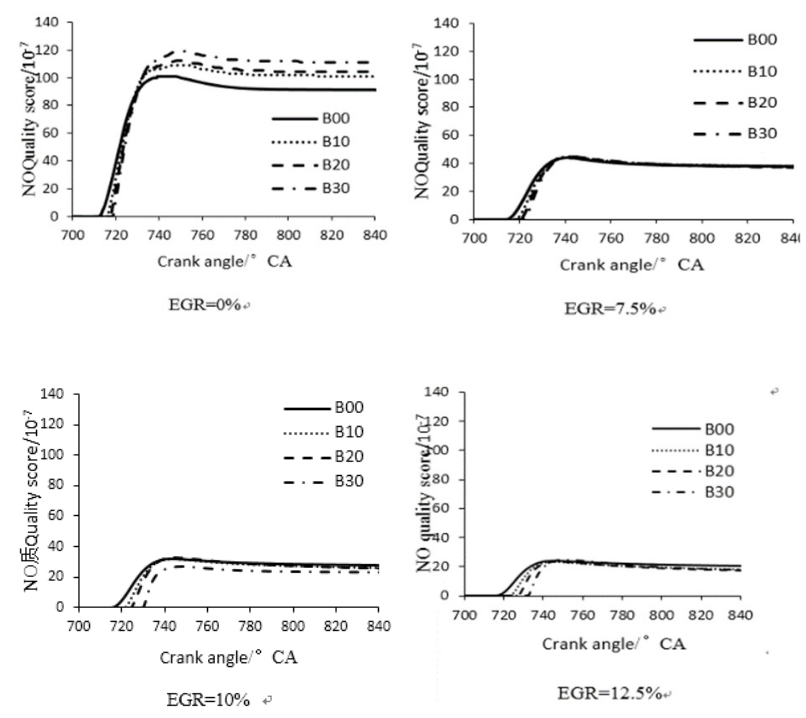

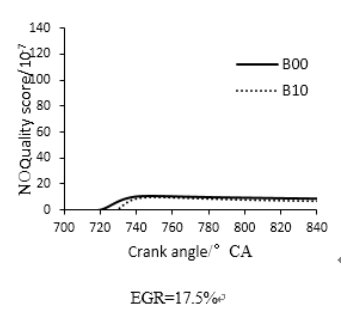

Fig.5 Effect of butanol blending ratio and EGR rate on NO emission
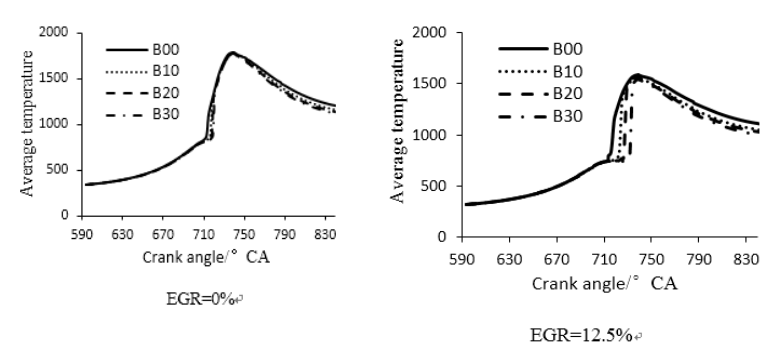

Figure.6 average temperature of in-cylinder combustion

\subsection{Effect of Butane Mixing Ratio and EGR Rate on Soot Emission}

Figure 7 is a plot of A4 production and consumption mass fraction at different EGR rates and butanol blend ratios. It can be seen from the figure that the mass fraction and consumption of soot precursor A4 decrease with the butanol blend ratio increase. In the highest point of the A4 generation image, the A4 formation of the low butanol blend ratio is much higher than the A4 formation of the high butanol blend ratio. The A4 mass fraction is gradually increased with the EGR rate at the low butanol blending ratio, and the rate of increase slowed down at high EGR rate. With the increase of EGR rate under the high butanol blending ratio, the A4 mass fraction first increases and then decreases. The consumption reached the highest at $7.5 \%$ when the EGR rate at $7.5 \%$.

The effect of butanol blending ratio on the amount of A4 production is that A4 is mainly produced in the premixed combustion stage. The increase of the butanol blending ratio will prolong the retardation period, and the fuel and air will be mixed more fully, reducing the amount of A4 production. The effect of the blending ratio of butanol on the consumption of A4: It can be seen from the above Figure6 that the temperature in the cylinder does not change much with the change of butanol blending ratio, and the increase of oxygen in butanol increases the oxygen content of the mixed gas, therefor the consumption of A4 is increased, and the amount of A4 generation is decreased.

The effect of EGR rate on the amount of A4 production is that under the low butanol blending ratio, the oxygen content in the cylinder decrease with the increase of EGR rate. The combustion is insufficient, and the amount of A4 is increased. High EGR rate at high butanol blending ratio results in longer fuel retardation. The fuel and air can be 
more thoroughly mixed, and the amount of A4 generated is lowered. The effect of EGR rate on A4 consumption: It can be seen from Fig. 7 that the A4 consumption rate decreases less at low blending ratios, mainly because the combustion is insufficient to facilitate the formation of soot. The above trend changes from the graph at the high butanol blend ratio. When the EGR rate is $0 \sim 12.5 \%$, the A4 consumption is an upward trend, mainly because the retardation period prolongs the increase of the cylinder temperature. When the EGR rate is higher than $12.5 \%$, the image is a downward trend, especially when the oxygen content in the cylinder is a relatively low level, the combustion is insufficient and the temperature is too low.
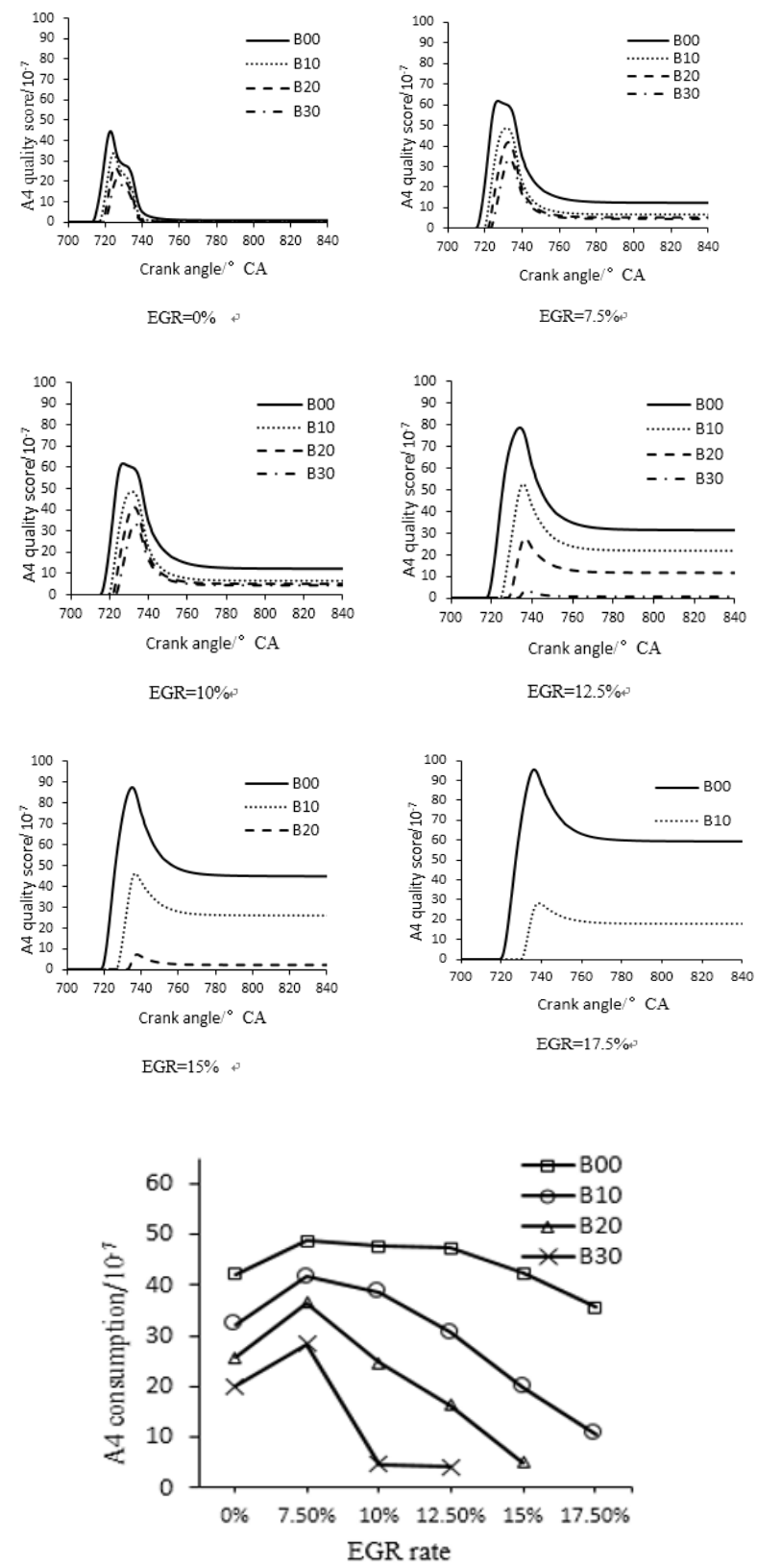

Fig.7 Effect of butanol blending ratio and EGR rate on A4

\subsection{Effect of Butane Mixing Ratio and EGR Rate on CO Emission}

Figures 8 and 9 are mainly CO mass fraction curves and $\mathrm{CO}$ emission mass fraction curves. It can be seen from the figure that under the same EGR rate, the amount of $\mathrm{CO}$ production decreases with the increase of butanol blending ratio, the initial generation time is extended backward, and the discharge mass fraction decreases with the increase of the blending ratio. For the discharge curve corresponding to different EGR rates at a certain angle of the crankshaft angle, the trend of $\mathrm{CO}$ generation increases at first time, and then gradually stabilizes with the increase of EGR rate. The emission of low butanol blending ratio increases first with the increase of EGR rate. It gradually became stable, and it showed a significant downward trend with the increase of EGR rate under the high butanol blending ratio.

Effect of butanol blending ratio on $\mathrm{CO}$ formation: On the one hand, butanol has lower cetane number than diesel, and the latent heat of vaporization of butanol is higher than that of diesel, which makes the combustion period prolonged, which contributes to the complete combustion of fuel and air. The CO generation amount is decreased, and the $\mathrm{CO}$ initial generation timing is delayed. On the other hand, theoretically, the calorific value of butanol is lower than fuel, the increase of butanol blending ratio reduces the maximum temperature of the cylinder, the duration of high temperature is shortened, and the amount of $\mathrm{CO}$ is increased, but it can be seen from Fig 6 under different blending ratios. The average temperature difference in the cylinder is very small. As the blending ratio increases, the higher oxygen content of butanol is beneficial to the combustion of the fuel more fully, and the $\mathrm{CO}$ is easily oxidized to $\mathrm{CO} 2$ in an oxygen-rich environment.

The effect of EGR rate on CO combustion generation is that the increase of EGR rate increases the inert gas in the cylinder, and the increase of specific heat capacity decrease the oxygen concentration in the intake air, which creates favorable conditions for CO generation when the EGR rate from $0 \%$ to $12 \%$. If the EGR rate more than $12.5 \%$, the dilution of the oxygen concentration at the low blending ratio is too large and the cetane number is lowered. The maximum combustion temperature in the cylinder is reduced by $200 \mathrm{~K}$ compared with EGR rate of 0 , The main reason is that the fuel is not fully burned and converted into carbon particles, so the amount of $\mathrm{CO}$ production appears to decline.

The effect of EGR rate on $\mathrm{CO}$ combustion emissions is that at high EGR rate, the butanol blending ratio increases, and $\mathrm{CO}$ emissions decrease because the cetane number of the blended fuel decreases, the retardation period is prolonged, and the oxygen content in butanol is increased. Conducive to more complete combustion of fuel, so $\mathrm{CO}$ emissions are reduced. 

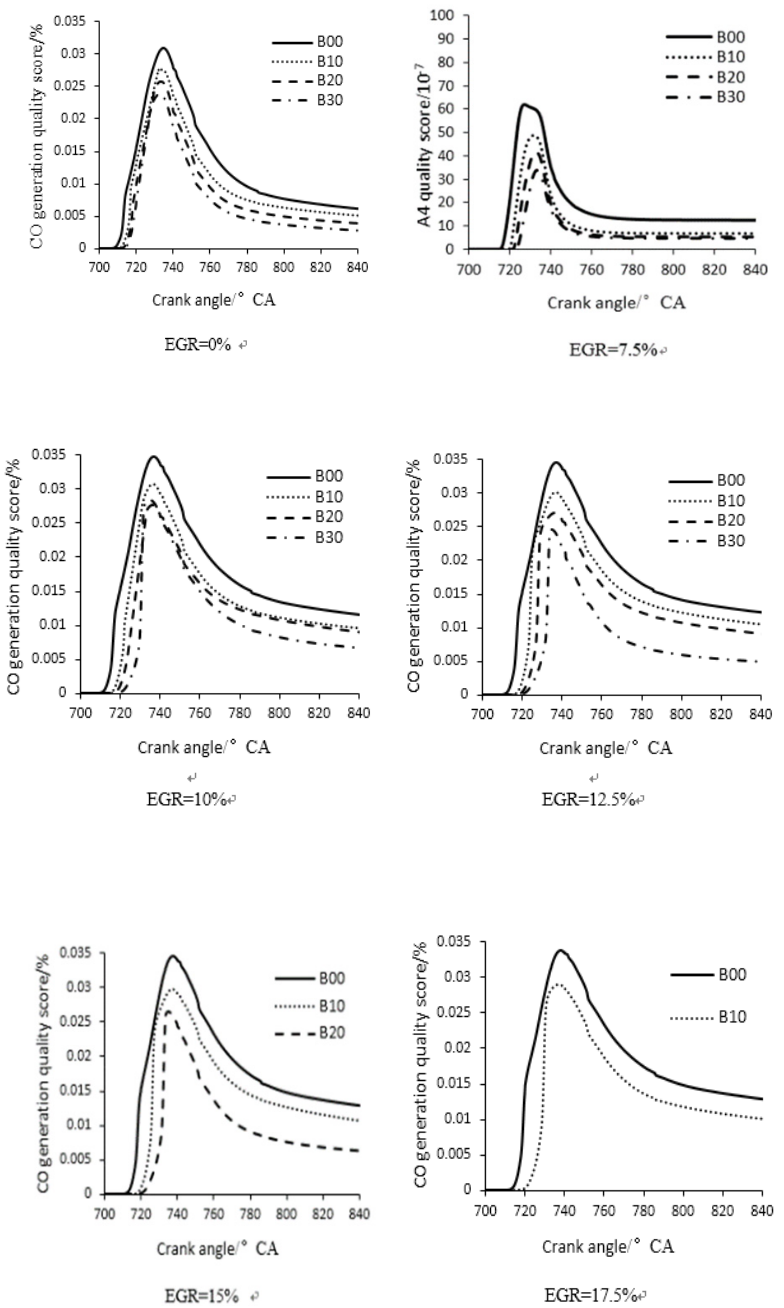

Fig.8 Effect of butanol blending ratio and EGR rate on CO mass fraction

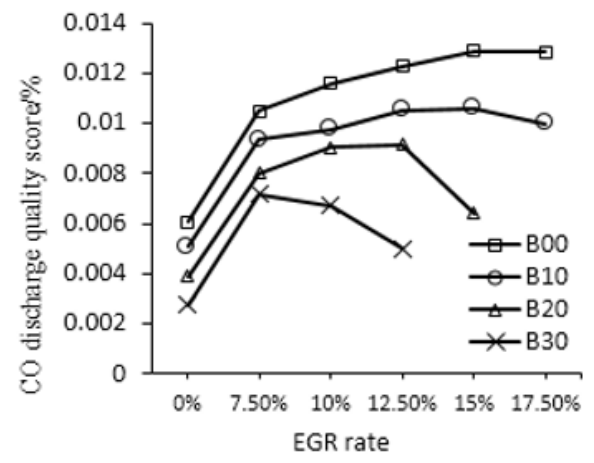

Fig.9 Effect of butanol blending ratio and EGR rate on CO emission mass fraction

\section{CONCLUSION}

In this paper, changing the butanol blending ratio and EGR rate, basing on the diesel fuel mixture combustion high pressure cycle simulation model, the experimental simulation calculation is carried out and the data is analyzed under the established conditions, the soot precursor, NO, The optimal blending ratio and EGR rate are selected for the comprehensive optimization.

From the analysis results, it can be seen that the butanol blending ratio has no obvious effect on reducing NO emissions, but has a significant effect on the formation and emission of A4, and also has a good improving effect on decreasing $\mathrm{CO}$ emission. The addition of EGR rate can achieve low temperature combustion effect, which can effectively decrease $\mathrm{NO}$ emissions.

Based on the above analysis, the blending ratio is at $\mathrm{B} 20$, and the EGR rate of $12.5 \%$ has the best effect on reducing the emission of $\mathrm{NO}$ and $\mathrm{CO}$, but the soot is not adversely affecting the dynamic properties.

\section{Acknowledgement}

Fund projects:

Fujian Natural Science Foundation funded projects(2017 J01486)

Fujian Natural Science Foundation funded Projects(2018J01499)

\section{Reference}

1. Qing Li, Kun Li, and Li Peng Wang. Ship Engineering, 38(01): 67-72, (2016).

2. Shao Zhu Huang. Marine Diesel Engine [M]. Economic and Trade Practice,1-3,(2005).

3. Hao zhong ,Huang,and Zhaojun Zhu,Jizhen. Experimental and numerical study of pre-injection effects on diesel- $\mathrm{n}$-butanol blends combustion[J]. Petroleum Business Technology,249,(2019).

4. [Yusri,Rizalman Mamat,M.K. Akasyah,M.F. China Shipbuilding, 156, (2019).

5. Constantine D. Rakopoulos,Dimitrios C. Rakopoulos,George M. Journal of Internal Combustion Engine,174,(2019).

6. Manish Saraswat,Nathi Ram Chauhan. Internal Combustion Engines and Parts, (2019).

7. Yusri,RizalmanMamat,. Journal of Thermal Science and Technology, 156, (2019).

8. min Geng Li, Chen Yang, bo Chen Xu. J o t Energy Institute, 92(3), (2019).

9. Research on Modeling and Performance Optimization of Marine Electronically Controlled Turbocharged Four-Stroke Diesel Engine[D]. Sun Jianbo. Dalian Maritime University,( 2007)

10. $\mathrm{Hu} \mathrm{Xu}$, Siyuan Sun, Jialiang Huang. China Shipbuilding,(2017), 2(222): 199-209.

11. Joshua D. Day,Jackson H. Birrell,Tyson J. Terry,Amy Clark,Phil Allen,Samuel B. St. Clair. Ecology and Evolution, 9(10),(2019).

12. Szu-Ying Wu,Cheng-Nan Lu. Medicine, 98(22),(2019).

13. Changbo,AN,Gaojun,Xiong.Progress on Fire and Procedia Engineering, 84, (2014). 
14. Penglei Li. Study on combustion and particulate matter emission characteristics of butanol/diesel blended fuel [D]. Jilin University, (2017). 